\title{
Mind Your Gap between Entry English Proficiency and Graduation Expectation
}

\author{
Uraiwan Sae-Ong* \\ Universiti Sains Malaysia \\ Penang, Malaysia \\ Shaik Abdul Malik Mohamed Ismail \\ Universiti Sains Malaysia \\ Penang, Malaysia
}

\begin{tabular}{|c|c|c|}
\hline Received & Revised & Accepted \\
\hline 28 August 2021 & 28 October 2021 & 15 November 2021 \\
\hline
\end{tabular}

\begin{abstract}
In recent years, the trend of teaching and learning English as a foreign language in Thai universities have changed drastically. This can be seen by the changes in the English as a foreign language curriculum and the manner it is being taught in schools as well as in the universities. The main objective of these changes is to prepare students to participate more aggressively in the ASEAN community, where English is the universal language. Thai universities launched a new policy about English graduation requirements aligned with the Common European Framework of Reference (CEFR). One area of interest is whether there is a gap between the entry English proficiency and English graduation expectation. Thus, this study sought to gauge the gap between English oral proficiency among the Thai 1st year undergraduates and the expected exit proficiency level (B2 CEFR). Results suggest that almost all 1st-year university students in Thailand have a tremendous gap between the real entry English oral proficiency level and the high expectations exit proficiency level. This information about the gap would allow the universities to prepare their students accordingly.
\end{abstract}

Keywords: English Oral proficiency test; CEFR; English oral proficiency gap; the English graduation requirement

\section{Introduction}

The Thai government has set the exit policy for all undergraduates to achieve the B2 level for the English language based on the CEFR (Common European Framework of Reference). This policy was in effect by 2020. The problem is how far the gap between the present Thai undergraduate English oral proficiency

* Corresponding Author: Sae-Ong, Uraiwan, uraiwan.saeong@gmail.com 
level and the expected exit level (B2 on CEFR) is. We must know this gap as it would mean whether these students would be able to graduate or not. It would also mean even if they were to graduate with B2 is that good enough to operate in the English speaking world (Ministry of Education, Thailand, 2016).

Leading Thai public universities such as Chulalongkorn, Thammasat, Mahidol, Kasetsart, and Prince of Songkla concern that English assessment is the key issue in the movement to reform education and improve student achievement to get a job and further study. Undergraduates are required to achieve the English graduation requirement from the standardised tests like TOEIC, TOEFL, or IELTS, according to the university's policy. These Thai public universities are increasingly using English graduation requirements as an indicator of their graduates (Several universities annual reports, Mahidol University (2017), Thammasat University (2017), Prince of Songkla University (2016), Kasetsart University (2016)).

It is important to acknowledge that the Ordinary National Educational Test $(\mathrm{O}$ NET) has not been designed to match to the CEFR, and so the potential for not aligning to the levels of the CEFR was recognised from the beginning. The cutscore at B2 level is critical because the Ministry of Education recommends that university students in Thailand should graduate with the required level of proficiency.

Therefore, if this study is not conducted, we would not know or be able to predict what would happen in 2020 when the policy comes into place. As such, we need to know the gap in the current ability and the expected goal (CEFR B2 level). It is expected that students' abilities will vary. As such, we need to categorize them into ability levels. This is important as it will allow us to know how much work needs to be done so that all of these students will graduate. This information will also allow instructors to prepare adequate resources to assist the students. This study aims to establish whether there is a gap in entry English oral proficiency among the Thai 1st year undergraduates and the expected exit proficiency level (B2 CEFR).

\subsection{Specific Focus}

The study considered four questions concerning the gap between the entry oral English proficiency status and the English graduation requirement; a) what is the entry English oral proficiency of the respondents based on standardised scoring? b) how big is the gap between the entry oral English proficiency status and the English graduation requirement? c) who among 1st-year Thai undergraduate students have the most significant gap in English oral proficiency? Furthermore, d) who among the students have the smallest gap in oral proficiency?

\section{A Brief Review of Literature}

\subsection{The Current Situation of English Language in Thailand}

The evidence of English proficiency has become a requirement for the admission or passport of non-native speakers in most universities in Thailand as well as many companies and organisations which require candidates a language certificate for employment. The issue of the Thai government policy and 
university policy on English proficiency, especially in communication skills, will be presented in detail.

As the Thai government has set the exit policy for all undergraduates to achieve the B2 level on the CEFR, this policy was in effect by 2020 in some Thai universities. The English exit exam is an English proficiency test that undergraduates take to meet the English proficiency requirement for graduation (Ministry of Education, Thailand, 2016).

CEFR adopted the theories from an action-oriented approach. The idea of this approach is setting a specific environment as a task for students to accomplish in a particular field of action by using their competence to achieve a given result. The framework category for spoken production assessment is based on a description of their academic fields.

Office of the Higher Education Commission of Thailand (2016) announced to raise and upgrade English standards in higher education institutions. First of all, Thai universities needed to set policies and goals to raise English standards in the curriculum and subsequently to improve students' English proficiency and equip them to achieve English graduation expectations with professional knowledge and skills in English communication. Second, Thai universities needed to design the policy and goals with clear indicators and evaluation strategies. Third, Thai universities needed to consider improving their teaching and learning in English by focusing on the achievement of the goals.

Furthermore, Thai universities are encouraged to consider extracurricular activities, learning processes, media, and environments to enhance students' self-learning. Next, Thai universities should test all students' English proficiency by using standardised tests, which can be compared to the Common European Framework of Reference for Languages (CEFR) or other standards. Thai universities may consider recording English proficiency test results in their academic transcript or certificate. Lastly, this policy was implemented in 2016 for first-year students.

According to several universities' annual reports of CEFR B2 alignment, Mahidol University (2017), Thammasat University (2017), Prince of Songkla University (2016), Kasetsart University (2016), there are several Thai universities have started driving their English graduation requirement policy. University such as Mahidol University (MU), Thammasat University (TU), Prince of Songkla University (PSU), and Kasetsart University (KU), which provided the details of English language requirements for graduates.

Table 1: English language requirements for Thai graduates at selected universities

\begin{tabular}{ccccccccc}
\hline Test types & MU & CEFR & PSU & CEFR & TU & CEFR & KU & CEFR \\
\hline TOEIC & 600 & B1 & 390 & A1 & 650 & B2 & 500 & B1 \\
\hline TOEFL & - & - & 450 & B1 & - & - & - & - \\
\hline TOEFL Ibt & 64 & B1 & - & - & 61 & B1 & - & - \\
\hline IELTS & 5 & B1 & 5 & B1 & 5.5 & B2 & - & -
\end{tabular}

All undergraduates must have one of the following qualifications as evidence of their English language ability according to the given table. As such, there are 
problems; for example, in terms of calibrating, each university has its way to calibrate the test type. The Ministry of Education of Thailand has set the B2 level in CEFR for Thai graduates without giving the calibration score. In TOEIC score, Thammasart University (TU) set at 650 score, which is the highest score among four universities, Mahidol University (MU) set at 600, Kasetsart University (KU) set at 500, and Prince of Songkla University (PSU) set at 390. As reflected in the scores requirement, there is a need to have a common score of calibration to set the standard.

\subsection{Ordinary National Educational Test in Thailand (O-NET) - English Subject}

The Ordinary National Educational Test (O-NET) is administered annually by the National Institute of Educational Testing Service to grade 6, grade 9, and grade 12 students in public and private schools in Thailand. The O-NET is a written examination administered face-to-face and delivered through paperpencil tests, which are aligned with the Basic Education Core Curriculum in Thailand. Besides, the O-NET comprises eight subjects: Thai language, social studies, English, mathematics, science, health and physical education, art, and vocational skills (The National Institute of Educational Testing Service, 2019).

Learners' speaking quality for grade 12 graduates set by the Ministry of Education in Thailand is focused on information or texts in everyday use such as news, announcement, and short official documents for receptive skills. For productive skills, O-Net is focused on both formal and informal conversations; hot issue, science and technology, beliefs, cultures, tradition, lifestyle, and occupation.

\subsection{Common European Framework of Reference for Languages (CEFR)}

The Common European Framework of Reference for Languages (CEFR) is an international standard for describing language ability, which describes English language ability, on a six-point scale, from A1 for English beginner users up to C2 for those who have English proficiency users. In Thailand, the B2 level in the CEFR standard is set as a goal for bachelor's degree graduates. The B2 level is for upper-intermediate users that mean graduates have to understand and be keen to communicate fluently in English in their field of specialisation. Moreover, they can provide ideas about the advantages and disadvantages of a topical issue (Council of Europe, 2018).

\subsection{The Importance of Oral English Proficiency in Thailand}

Thai universities require undergraduates to focus on English oral proficiency because it is like a passport to be employed. Many Thai universities have realised that English oral proficiency is essential for students who will need to seek employment not only in Thailand (especially multi-national companies) but also in the ASEAN community and beyond. It has been noted that the biggest reason for unemployment among Thai university graduates is their poor English oral proficiency.

In the real workplace, English oral proficiency of university students is stated at average to low quality as similar to other countries in ASEAN (Yin, 1988; Gordon, 2002; Orsi and Orsi, 2002; Riemer, 2002; Cowling, 2007; Yasin et al., 2010; Jarupan 2013). Prachanant (2012) studied, the needs, functions, and 
problems of the English language use tourism employees. Findings revealed that English oral proficiency is the most important, then listening, reading, and writing. Likewise, Rochanasak, Klinjuy, Samanit, and Nilamai (2019) recommended that for university students and job seekers were encourage to have capabilities in English speaking.

Also, Wei \& Chung (2019) presents that the participants in this study had high expectations towards new graduates' English oral proficiency compared to the other three skills-writing, reading, and listening.

\section{Method}

\subsection{Participants}

Participants in this study were 324 of first-year Thai undergraduate students selected by purposive sampling techniques according to their English proficiency based on CEFR levels from A1 to B2. Including ten subject matter experts (SMEs) served on the panels that focused on mapping scores from the ONet test onto the CEFR.

\subsection{Data Collection}

There are three instruments in the study: the modified Angoff item rating forms, English Oral Proficiency Test (OPT), and rating form for English oral proficiency test.

First of all, the Modified Angoff item rating forms were divided into three rounds, three forms according to Modified Angoff theory. These forms were implemented with the O-Net 2018. Secondly, the OPT was employed to test the English oral proficiency of 324 university students. Lastly, this study conducted an analytic approach, which is the five raters give separate scores for several different language features according to CEFR speaking scales of A1 to C2 (University of Cambridge ESOL Examinations, 2009). a) how big is the gap between the entry oral English proficiency status and the English graduation

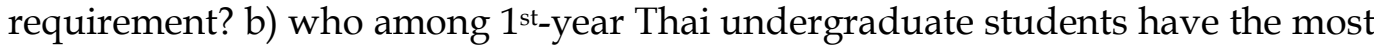
significant gap in English oral proficiency? Furthermore, c) who among the students have the smallest gap in oral proficiency?

\section{Findings}

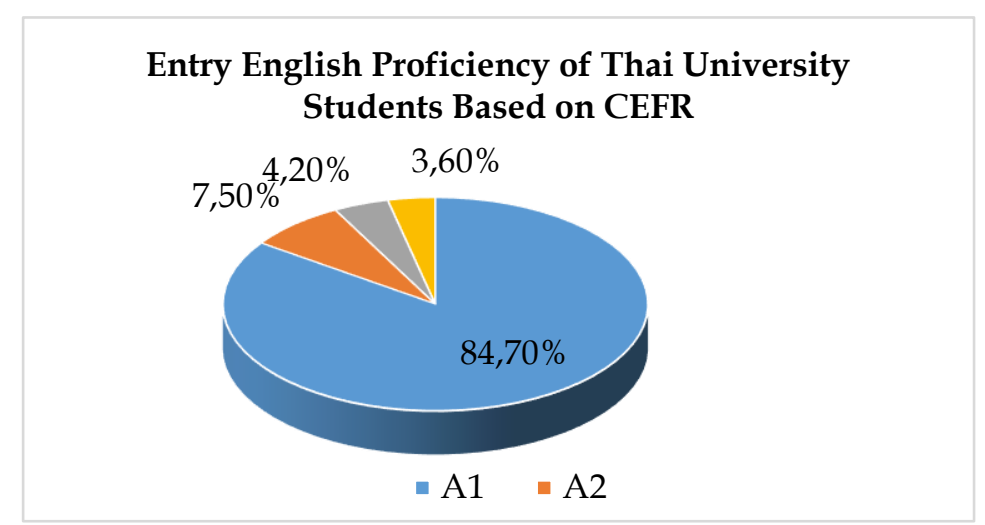


Figure 1. Entry English Proficiency of Thai University Students Based on CEFR levels

To answer the first research question, how big the gap between the entry oral English proficiency status and the English graduation requirement is, figure 1 represents the entry English oral proficiency status of Thai university students based on standardised scoring. According to the ministry in Education in Thailand announce that Thai university students must have a B2 level based on CEFR before graduation. Otherwise, they cannot get a Bachelor's degree. The result of this phase was showed that almost $95 \%$ of 1 st-year university students achieved English proficiency below the B2 level. It is a big gap for $85 \%$ of university students to achieve at least three higher levels from the A1 level to the B2 level.

Firstly, the methodology used in this phase was to compare students' O-Net test scores at each CEFR level from A1 to B2 with English Oral Proficiency Test (OPT) scores.

Table 2. The O-NET cut-off scores according to the CEFR levels

\begin{tabular}{ccc}
\hline CEFR levels & Cut off score & O-NET \\
\hline A1 & N/A & - \\
\hline A2 & 53 & $53 \%-64.75 \%$ \\
\hline B1 & 65 & $65 \%-75.75 \%$ \\
\hline B2 & 76 & $76 \%-100 \%$ \\
\hline C1 & N/A & - \\
\hline C2 & N/A & - \\
\hline
\end{tabular}

The descriptive statistics were illustrated in Round 3 judgment according to the modified Angoff method. The mean cut-off scores for A2, B1, and B2 are rounded to 53, 65, and 76, respectively, for O-Net scores in English subject. In Round 3, B1 cut-off scores are slightly greater than those of Round 2, while A2 and B2 cut-off scores remain the same. Moreover, the highest standard deviation is at $\mathrm{A} 2$, as is the highest SEJ. 


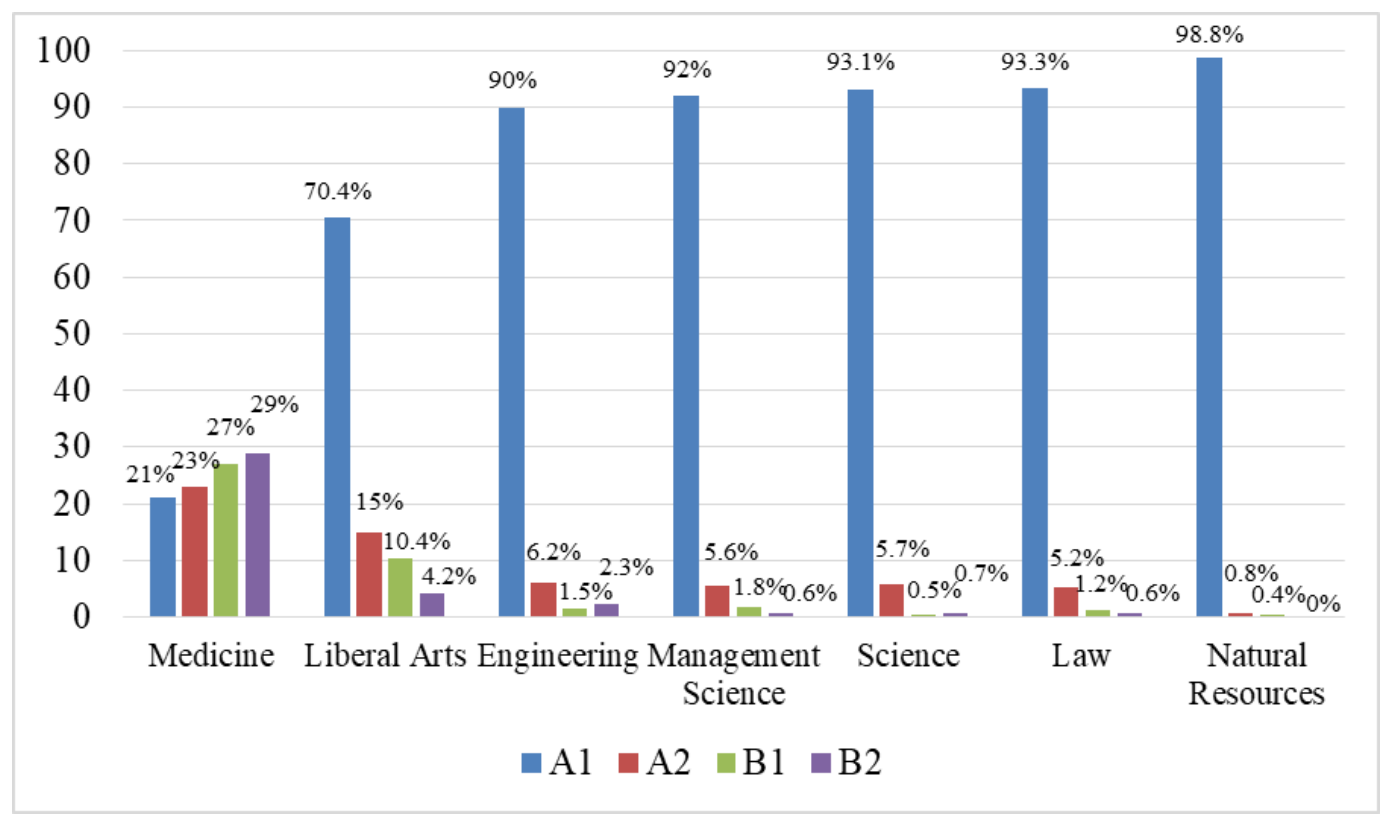

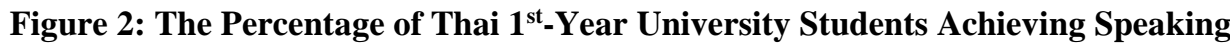
Performance at CEFR level Based on Faculties

In terms of Faculty ranking, the findings of this study reflected that student from the Faculty of Natural Resources had the most significant gap in English oral proficiency. Almost all students, approximately 99\%, were at A1 level based on CEFR. Besides that, the data presented revealed that there was none from the faculty of Natural Resources who was able to reach B2 level - followed by students from the Faculty of Law and Faculty of Science, which about $93 \%$ were at A1 level. The percentage of A1 students was from the Faculty of Management Sciences, Faculty of Engineering, and Faculty of Liberal Arts, 92\%, 90\%, and 70\%, respectively. As expected, more medical students had higher English proficiency, which was approximately $20 \%$ of students scoring A1 from the Faculty of Medicine.

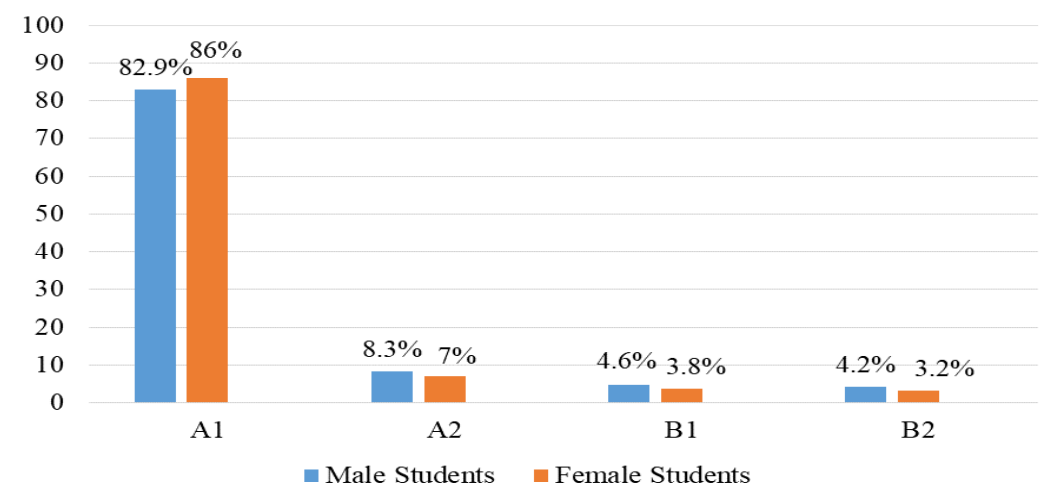

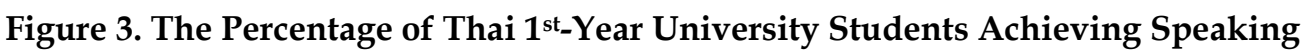
Performance at the CEFR Level Based on Genders

In terms of gender, about $86 \%$ of female students and $83 \%$ of male students were at the A1 level. Surprisingly, male students have a few percentages higher than female students at A2, B1, and B2 levels. The findings presented that female student had a more massive gap in entry English oral proficiency levels than male students. 
Lastly, who among 1st year Thai undergraduate students have the biggest and the smallest gap in the English oral proficiency, figure 3 presents the percentage of Thai university students achieving speaking performance at CEFR level. The results were collected from the faculties, which are from OECD/UNESCO (2016), which investigated the international standard classification of education: social sciences, business, administration and law, natural sciences, mathematics and statistics, engineering, and agriculture.

The findings from the current study exposed that student from the Faculty of Medicine had the smallest gap in English oral proficiency. Further analysis showed that one-third of the Thai first-year university students from the Faculty of Medicine achieved the B2 level, which was the required level for graduation. The English oral proficiency level of students from the Faculty of Medicine, followed by B1, A2, and A1 levels were $27 \%, 23 \%$, and $21 \%$, respectively.

In a nutshell, based on the results in figure 3, among 1st-year Thai undergraduate students, the faculty of Natural Resources has the most significant gap in English oral proficiency. Almost all the students were at the A1 level. Besides, the data presented that nonentity reached a B2 level in CEFR. On the other hand, students in the faculty of Medicine have the smallest gap in oral proficiency.

\section{Conclusion}

This study has successfully established the gap between the English oral proficiency of the $1^{\text {st }}$ year Thai undergraduates and the expected exit level proficiency as required by the Ministry of Education in Thailand at B2 level. What we found, it is a remarkable issue for students because the level is not at the expected level. The main reasons are that there is no proper calibration, and there is no proper work done in the Thai context. It means that Thai universities and also schools were not ready to encourage students to achieve the expected level. Therefore, this finding has highlighted the gaps and some more work to be done. We may need to utilize this information so that the next step is to title the teaching and learning process. Everybody from the start can engage now the new instrument, and we can engage the Thai students' progress and prior to the exit year as more work to be done to prepare the students.

\section{Acknowledgment}

The author is gratefully and heartily thankful to Associate Professor Dr. Shaik Abdul Malik Mohamed Ismail, supervisor, for his encouragement, guidance, and support from the initial to final level towards this study. Moreover, especially appreciation is given to the Thai university students as well as administrators and lecturers for their great participation in the conduct of the study.

\section{References}

Council of Europe. (2018). Common European Framework of Reference for Languages: Learning, Teaching, Assessment: Companion Volume with New Descriptors. www.coe.int/lang-cefr. 
Cowling, J. D. (2007). Needs analysis: Planning a syllabus for a series of intensive workplace courses at a leading Japanese company. English for Specific Purposes. 26: 426-429.

Gordon, J. (2002). An ESP program for entry-level manufacturing workers. In T. Orr (Ed.), $\quad$ English for specific purposes: case studies in TESOL practice series. pp. 147-160. Virginia: TESOL Inc.

Jarupan, S. (2013). The English Oral Communication Competency of Thai Engineering Students International Journal of Scientific and Research Publications, Volume 3, Issue 3.

Kasetsart University. (2016). https://offic.src.ku.ac.th/student/news/rules/Eng59.pdf.

Mahidol University. (2017). http://www.student.mahidol.ac.th/newstudent/ manual61/6rules20.html?fbclid=IwAR1ov5t3vy311M9ANU_C8gA7GhlJPLzIw 5 ynzaYWxopQYKYXTW4dTOpFGs.

Ministry of Education, Thailand (2016). English Language Reforming Policy. file:///C:/Users/HP/AppData/Local/Temp/5705140101.pdf.

OECD/UNESCO (2016), Education in Thailand: An OECD-UNESCO Perspectiv Reviews of National Policies for Education, OECD Publishing, Paris. http://dx.doi.org/10.1787/9789264259119-en

Office of the Higher Education Commission of Thailand (2016). Bangkok.

Orsi, L.and Orsi, P. 2002. An ESP program for brewers. In T. Orr (Ed.). English for Specific Purposes: case studies in TESOL practice series. Verginia : TESOL. Inc., 175-188.

Prachanant, N. (2012). Needs Analysis on English Language Use in Tourism Industry. Elsevier Ltd.

Prince of Songkla University. (2016). http://www.mcs.sat.psu.ac.th/file/engBsc.pdf.

Riemer, M.J. (2002). English and Communication Skills for the Global Engineer. Global Journal of Engineering Education. 6 (1): 91-100.

Rochanasak, S., Klinjuy R., Samanit, S., and Nilamai, V. (2019). Essential Skills for Thailand 4.0: The Importance of Education Corresponded to Employment Scenarios, and Building Self-Competent Immunity Pertaining to Technological Disruptions. Veridian E-Journal, Silpakorn University. Humanities, Social Sciences, and Arts Volume 12 Number 3 May-June 2019.

Thammasat University. (2017). Annual Report. https://reg.siit.tu.ac.th/registrar.pdf.

The National Institute of Educational Testing Service (Public Organisation). (2019). http://www.niets.or.th/en/

University of Cambridge ESOL Examinations. (2009). Example of Speaking Performance at CEFR Levels A2 to C2.

Wei, X., \& Chung, J. (2019). Analyzing Expectations of Business Administrators on Key Skills Required for Entry-Level Jobs in Thailand. Journal of Global Business Review Vol. 21 No.1 January -June 2019.

Yasin, A., W. Shaupil, A. Mukhtar, N. Ghani and F. Rashid. (2010). The English proficiency of Civil Engineering students at a Malaysian polytechnic. Asian Social Science. 6 (6): 161-170.

Yin, K. M. (1988). ESP for engineers: a reassessment. ESL Journal. 42(2): 102-108. 